\title{
Criticality of physical/social distancing, handwashing, respiratory hygiene, and face-masking during the COVID-19 pandemic and beyond
}

\author{
Farid Rahimi ${ }^{1}$ and Amin Talebi Bezmin Abadi $^{2}$ \\ ${ }^{1}$ The Australian National University \\ ${ }^{2}$ Tarbiat Modares University
}

May 14, 2020

\begin{abstract}
Physical/social distancing, handwashing, respiratory hygiene, and face-masking have been recommended as realistic counterstrategies to control the COVID-19 pandemic. These strategies have been critical in the fight against the present pandemic in many countries. Here, we detail the background to such countermeasures, present some examples in different settings, and finally emphasize that they should remain in place worldwide as a cultural and behavioral "new normal" until a vaccine or a decisive treatment for COVID-19 is developed and made available globally.
\end{abstract}

The outbreak caused by the "severe acute respiratory syndrome coronavirus 2" (SARS-CoV-2) distressed the Wuhan residents in December 2019. Many suffering the resultant "unknown pneumonia" were initially admitted to Wuhan hospitals; the predominant symptoms included pyrexia, malaise, dry cough, and sore throat. A fraction of the patients reportedly suffered the complications which culminated in acute respiratory distress syndrome, septic shock, or multiorgan failure, and death. By the end of January 2020, the World Health Organization (WHO) announced the outbreak as a public-health emergency and later, on March 11, declared the COVID-19 a pandemic. Interestingly, the Australian government had declared COVID-19 as a "disease of pandemic potential" on 21 January, ${ }^{1}$ ahead of WHO. By May 12, 2020, confirmed cases worldwide ${ }^{2}$ had totaled 4,277,720 with $>50,000$ new cases registered daily. Meanwhile, our understanding of the pathogenesis, prognosis, symptoms, and case-fatality rate of COVID-19 is still limited but growing fast. $^{3-11}$

Outbreak of the COVID-19 pandemic inevitably led to realistic, mandatory restrictive countermeasures in many countries, causing uncertainty for millions of people with resultant unprecedented effects on economy and morale -importantly livelihood and job losses - which will require many years to recuperate. Thus, eliminating the ongoing impact of the pandemic on the social fabric, morale, and psychosocial and economic wellbeing is critical. Developing prophylactic vaccines or antiviral therapies for SARS-CoV-2 will perhaps require few years of research, testing, and clinical trials. ${ }^{12}$ Some drugs (e.g., chloroquine and hydroxychloroquine) have been touted to be effective but have been shrouded with controversy. ${ }^{13}$

Because respiratory viruses, including SARS-CoV-2, transmit from person to person by virally loaded aerosols, any effective measure to disrupt this transmission mode will reduce the chance of infection. Quarantine has historically been effective in mitigating and managing contagious epidemics. Thus, many countries have barred mass-gatherings and encouraged self-isolation, in-house quarantine, and study or work from home to lower the chance of viral transmission. More than 210 countries, except Sweden and par- 
tially the United Kingdom, had mandated such strict measures. Social and religious ceremonies have been barred or postponed. In Australia, for example, public gatherings were limited and distancing principles, including $1.5 \mathrm{~m}$ between individuals and $4 \mathrm{~m}^{2}$ area per person, have been mandated if unrelated people come together. ${ }^{14,15}$ Further, sporting events have been cancelled or postponed; for example, the Champions League has been cancelled, and the 2020 Tokyo Olympic Games postponed. Scientific research, schooling, and universities have been profoundly affected in many countries. ${ }^{16}$ The resultant economic and morale repercussions demand new solutions to fighting the pandemic and minimizing its negative impacts because the dynamic and evolving nature of the pandemic may hint that the counterstrategies may not be efficiently maintainable. Presuming that an effective drug or a preventive vaccine for COVID-19 is distant, one may ask, "how long must the counterstrategies continue globally?" We do not intend here to undermine the importance of developing antiviral drugs or vaccine projects, but to highlight the importance of public's behavioral, cultural, and habitual changes for the pandemic's duration and in the immediate future when some restrictions potentially gradually ease in some countries, e.g., Australia ${ }^{17,18}$ and New Zealand. ${ }^{19}$

Upholding the strict quarantine/isolation rules, social distancing, respiratory and hand hygiene, and wearing the protective masks is important for the future. Physical distancing while keeping regular contacts with family members and friends will help with maintaining psychosocial wellbeing and morale. Physical distancing is needed during uncontrolled outbreaks, when contagion rate, the risk of an epidemic, and the case-fatality rates of confirmed cases are high. Though compliance may differ from culture to culture and nation to nation, the countermeasures are seemingly effective in reducing the viral spread from asymptomatic carriers or from patients to healthy individuals. For example, face-masking reportedly efficiently protects against SARS-CoV-2 transmission. ${ }^{20}$ We admit that any recommendation in controlling the pandemic should be based on growing evidence experienced by different nations. We propose that the restrictive countermeasures should continue for at least 8-12 months until normal social activities can phase in. Even afterwards, the rules of social/physical distancing, frequent handwashing, respiratory hygiene, and face-masking will remain utterly critical. The compliance with such measures should be encouraged through public education and awareness campaigns to ensure such behavioral, habitual, and cultural changes into the future.

\section{References}

1. Galloway A. How Australia bypassed WHO's China problem. [News]. 2020; https://www.smh.com.au/politics/federal/how-australia-bypassed-the-who-s-china-problem-20200416p54kmc.html. Accessed 20 April, 2020.

2. Worldometer. Coronavirus (COVID-19) mortality rate. 2020; https://www.worldometers.info/coronavirus/. Accessed 12 May, 2020.

3. Pianegonda E. What is Kawasaki disease, what are the symptoms and is it linked to coronavirus? - ABC News. 2020; https://www.abc.net.au/news/2020-04-29/kawasaki-disease-symptoms-is-it-linked-coronavirusin-australia/12197008. Accessed 30 April, 2020.

4. Zimmer K. What do antibody tests for SARS-CoV-2 tell us about immunity? 2020; https://www.thescientist.com/news-opinion/what-do-antibody-tests-for-sars-cov-2-tell-us-about-immunity-67425. Accessed 23 April, 2020.

5. Zheng YY, Ma YT, Zhang JY, Xie X. COVID-19 and the cardiovascular system. Nat Rev Cardiol. 2020;17(5):259-260.

6. Zaman S, MacIsaac AI, Jennings GLR, et al. Cardiovascular disease and COVID-19: Australian/New Zealand consensus statement. The Medical Journal of Australia. 2020:1.

7. Yeager A. Lost smell and taste hint COVID-19 can target the nervous system. 2020; https://www.thescientist.com/news-opinion/lost-smell-and-taste-hint-covid-19-can-target-the-nervous-system-67312. Accessed 30 April, 2020. 
8. Xiao L, Sakagami H, Miwa N. ACE2: The key molecule for understanding the pathophysiology of severe and critical conditions of COVID-19: Demon or angel? Viruses. 2020;12(5).

9. Winter L. Nearly all NYC-Area COVID-19 hospitalizations had comorbidities. 2020; https://www.thescientist.com/news-opinion/nearly-all-nyc-area-covid-19-hospitalizations-had-comorbidities-67476. Accessed 30 April, 2020.

10. Vincent JL, Taccone FS. Understanding pathways to death in patients with COVID-19. Lancet Respir Med. 2020;8(5):430-432.

11. Broadfood M. DNA could hold clues to varying severity of COVID-19. 2020; https://www.thescientist.com/news-opinion/dna-could-hold-clues-to-varying-severity-of-covid-19-67435. Accessed 23 April, 2020.

12. Dong L, Hu S, Gao J. Discovering drugs to treat coronavirus disease 2019 (COVID-19). Drug Discov Ther. 2020;14(1):58-60.

13. Grens K. Journal publisher concerned over hydroxychloroquine study. 2020; https://www.thescientist.com/news-opinion/journal-publisher-concerned-over-hydroxychloroquine-study-67405. Accessed 15 April, 2020.

14. Australian Government Department of Health. Limits on public gatherings for coronavirus (COVID-19). 2020; https://www.health.gov.au/news/health-alerts/novel-coronavirus-2019-ncov-health-alert/how-toprotect-yourself-and-others-from-coronavirus-covid-19/limits-on-public-gatherings-for-coronavirus-covid-19. Accessed 20 April, 2020.

15. ABC. What are stage 4 coronavirus restrictions and what could those measures look like for Australians? 2020; https://www.abc.net.au/news/2020-04-11/coronavirus-what-are-stage-four-restrictions-inaustralia/12141480. Accessed 20 April, 2020.

16. Schleunes A. Furloughs and pay cuts announced for U of Arizona employees. 2020; https://www.thescientist.com/news-opinion/furloughs-and-pay-cuts-announced-for-u-of-arizona-employees-67444. Accessed 23 April, 2020.

17. Prime Minister of Australia. Update on Coronavirus measures | Prime Minister of Australia. 2020; https://www.pm.gov.au/media/update-coronavirus-measures-08may20. Accessed 12 May, 2020.

18. Tomlin S, Mills V. Mystery transmission highlights concerns over COVID-19 complacency in the Kimberley - ABC News. 2020; https://www.abc.net.au/news/2020-05-12/covid-19-kimberley-mystery-transmissioncauses-concern/12237894. Accessed 12 May, 2020.

19. Clarke M. New Zealand's strict coronavirus restrictions to ease this week - ABC News. 2020; https://www.abc.net.au/news/2020-05-11/new-zealand-jacinda-ardern-coronavirus-restrictionscovid19/12234940. Accessed 12 May, 2020.

20. Leung NHL, Chu DKW, Shiu EYC, et al. Respiratory virus shedding in exhaled breath and efficacy of face masks. Nat Med. 2020. 